- Health staff must be trained to use the appropriate educational methods.

School of Health and Community Care,

KEITH TONES

Leeds Metropolitan University,

Calverley Street,

Leeds LS1 3EH

1 Tones BK. Health promotion-a new panacea? fournal of the Institute of Tones BK. Health promotion-a

2 Tones K, Tilford S. Health education: effectiveness, efficiency and equity. London: Chapman Hall, 1994

3 World Health Organisation. Health promotion: a discussion document on the concepts and principles. Copenhagen: WHO, 1984.

4 World Health Organisation. Ottawa charter for health promotion. An international conference on health promotion, November 17-21. Copenhagen: WHO, 1986

5 Tones K. Health education, behaviour change and the public health. In Dettels R, McEwen J, eds. Oxford textbook of public health. Oxford: Oxford University Press, 1997.

6 Tones K. Radicalism and the ideology of health education. Health Education Research 1993;8:147-50.

7 Green LW, Lewis FM. Measurement and evaluation in health education and health promotion. Palo Alto, CA: Mayfield, 1986.

8 Sarvela PD, McDermott RJ. Health education evaluation and measurement: a practitioner's perspective. Madison, WI: Brown and Benchmark, 1993 .

9 Brook R, Lohr K. Efficiency, effectiveness, variations and quality. Medical Care 1985;23:710-22.

10 International Union for Health Promotion and Education. Improvement of the effectiveness of health education an health promotion. Utrecht: Dutch Cenre for Health Promotion, 1994.

11 Harker P. Promotion of breastfeeding maintenance. Briefing review No 2. Bristol: Department of Social Medicine, 1996.

12 Harker P. Health visitor prevention of child home accidents. Briefing review No1. Bristol: Department of Social Medicine, 1996.

13 Contento I. Nutrition education and implications. Fournal of Nutrition Education 1995;27:special issue.

14 Colland VT. Learning to cope with asthma: a behavioural self-management programme for children. Patient Education and Counselling 1993;22:141-52.

5 Schou L, Locker D. Oral health: a review of the effectiveness health education and health promotion. Utrecht: Dutch Centre Health Promotion, 1994.

16 Sogaard AJ, Holst D. The effect of different school based dental health education programmes in Norway. Community Dent Health 1988;5:169-84.

17 Holund U. Promoting change of adolescents sugar consumption: the 'Learning by Teaching' study. Health Education Research 1990;5:451-8.

18 Mackie IC, Worthington HV, Hobson P. A spoonful of sugar-free helps caries levels go down. Fournal of the Institute of Health Education 1992;30: 60-5.

19 Kuthy RA, Durkee J. Education: a key to fluoridation compliance. F Public Health Dent 1985;45:247-51.

20 Smith KG, Christen KA. A fluoridation campaign: the Phoenix experience. $\mathcal{f}$ Public Health Dent 1990;50:126-35.
21 Towner E. Unintentional injuries in childhood: a review of the effectiveness of health education and health promotion. Utrecht: Dutch Centre for Health Promotion, 1994.

22 Reisinger KS, Williams AF, Wells JK, John CE, Roberts TR, Podgainy HJ. Effect of paediatrician's counselling on infant restraint use. Pediatrics 1981; 67:201-6.

23 Schelp L. Community intervention and changes in accident pattern in a rural Swedish municipality. Health Promotion 1987;2:109-25.

24 Colver A, Hutchinson PJ, Hudson EC. Promoting children's home safety. BMF 1982;285:1177-80.

25 Katcher ML, Landry GL, Shapiro MM. Liquid-crystal thermometer use in pediatric office counselling about tap water burn prevention. Pediatrics 1989;83:766-71.

26 Thomas K, Hassanein RS, Christopherson ER. Evaluation of group well-child care for improving burn prevention practices in the home. Pediatrics 1984;74:579-82.

27 Thomson JA, Ampofo-Boateng K, Pitcairn T, Grieve R, Lee DN, Demetre JD. Behavioural groups training of children to find safe routes to cross the road. Br F Educ Psychol 1992;62:173-83.

28 Jones DA, West R, Newcombe RG. Maternal characteristics associated with the duration of breast-feeding. Midwifery 1986;2:141-6.

29 Frank DA, Wirtz S, Sorenson JW, Heeran T. Commercial discharge packs and breast-feeding counselling: effects on infant-feeding practices in a randomised trial. Pediatrics 1987;80:845-54.

30 Johnson CA, Garza C, Nichols B. A teaching intervention to improve Johnson CA, Garza C, Nichols B. A teaching intervention to impration
breastfeeding success. Fournal of Nutrition Education 1984;16:19-22.

31 Kistin N, Abramson MS, Dublin P. Effect of peer counselors on breastfeeding initiation, exclusivity, and duration among low-income urban women. Fournal of Human Lactation 1994;10:11-6.

32 Koblinsky SA, Guthrie JF, Lynch L. Evaluation of a nutrition education program for Head Start parents. Fournal of Nutrition Education 1992;24:413.

33 Perry CL, Mullis RM, Maile ML. Modifying the eating behavior of young children. Fournal of School Health 1985;55:399-402.

34 Aggleton P. Sexual behaviour and HIVIAIDS: a review of the effectiveness of health education and health promotion. Utrecht: Dutch Centre for Health Promotion, 1994.

35 Jemmott J, Jemmott LS, Fong GT. Reductions in HIV risk-associated sexual behaviours among black male adolescents: effects on AIDS prevention intervention Am f Public Health 1992;82:372-7.

36 Walter H, Vaughan R. AIDS risk reduction among a multiethnic sample of urban high school students. $\mathscr{F} A M A$ 1993;270:725-30.

37 Hosman C, Veltman N. Prevention in mental health: a review of the effectiveness of health education and health promotion. Utrecht: Dutch Centre for Health Promotion.

38 Olweus D. Bullying among schoolchildren: intervention and prevention. In: Peters V, McMahon RJ, Quinsey VL, eds. Aggression and violence throughout the life span. Newbury Park: Sage, 1992.

39 Barker W, Anderson R, Chalmers C. Child protection: the impact of the child development programme. Bristol: University of Bristol Early Childhood development programme. Bri

40 Berruetea-Clement JR, Schweinhaert LJ, Barnett WS, Epstein AS, Weikart DP. Changed lives: the effects of the Perry Preschool Program on youths through age 19. Michigan: High Scope Press, 1984.

\title{
Vitamin A prophylaxis
}

It has been little more than a decade since the initial observation of the dose dependent relation between the severity of vitamin A deficiency and childhood mortality, ${ }^{1}$ quickly followed by the publication of a controlled trial in which children of preschool age, randomised to receive large doses of vitamin A every six months, died at only two thirds (or less) the rate of control subjects. ${ }^{2}{ }^{3}$ In the short interval since this trial, an initially sceptical scientific community has declared control of vitamin A deficiency a major international goal ${ }^{4-6}$ and potentially one of the most cost effective of all health interventions. ${ }^{7}$

The story did not begin in the 1980s. A host of animal studies and anecdotal clinical reports during the first third of the century, soon after vitamin A was discovered, suggested a close, potentially causal relation between vitamin A status and morbidity and mortality from infection. These are detailed elsewhere. ${ }^{8}$

\section{Vitamin A prophylaxis and mortality}

For ethical and logistic reasons the observational study ${ }^{1}$ has never been repeated, though a large number of intervention trials have been carried out. Eight were initially considered to be suitably rigorous for inclusion in an independently commissioned meta-analysis (table 1 ). ${ }^{9}$ The results were remarkably similar, particularly given the wide differences in culture, dietary habits, disease patterns, and malnutrition of the populations studied, the differences in study design, and the variation in the potential effectiveness of the strategies used to improve vitamin A status. ${ }^{210-16}$

On an intent to treat basis, six of the eight studies recorded a statistically significant reduction in mortality among children assigned to receive vitamin A supplements (19 to $54 \%$ ), even though not all those assigned vitamin A complied with the treatment. ${ }^{28}$

\section{Negative results}

Two 'outlier studies', in which no reduction in mortality was observed, deserve mention. The Hyderabad trial ${ }^{13}$ had a series of problems that only became apparent after publication from an exchange of letters to the editor: children were routinely examined and treated for disease each week by specially trained health workers. This may explain why both the treatment and control arms experienced mortality much lower than anticipated. This general reduction in mortality drastically reduced the power of the study to detect an effect attributable to the vitamin A supplement (mean reduction 6\%, 95\% confidence interval 
-50 to $50 \%) .{ }^{9}$ In addition, the study had a large and differential loss to follow up and low levels of compliance.

The Sudan trial ${ }^{16}$ probably did not establish a meaningful difference in vitamin A status between its two study groups. It is likely that the study children were not particularly deficient to begin with: almost half lived in homes with sanitary facilities and piped-in water, hardly representative of the economic status and living conditions of most children in the developing world.

Importantly, the senior authors of both these studies have subsequently supported the value of improving vitamin A status as a means of reducing childhood mortality. ${ }^{817}$

\section{Infectious morbidity and mortality}

Longitudinal observational data have suggested that vitamin A status can affect the incidence of infectious diseases. ${ }^{18} 19$ Intervention trials, however, have not confirmed a causal relation; instead, improving vitamin A status primarily reduces the severity of infectious episodes, ${ }^{1420}$ particularly life threatening diarrhoea and measles (table 2).

\section{Measles}

In the four community based prophylaxis trials in which cause specific mortality was ascertained, mortality from measles was reduced by roughly 50\% (table 2). ${ }^{112}{ }^{14}{ }^{15} \mathrm{In}$ the one trial which did not arrive at this conclusion, ${ }^{15}$ the data presented in the published paper clearly prove otherwise (though given the sample size the large clinical difference was not statistically significant). Remarkably, the treatment with high doses of vitamin A of children admitted to hospital with moderate to severe measles reduces mortality to a similar extent, ${ }^{21-23}$ strongly suggesting that the beneficial impact is secondary to the correction of the underlying vitamin A deficiency and not to a non-specific adjuvant response related to the large dose. ${ }^{8}$ Treatment with large doses of vitamin A (200 000 IU on two successive days) also reduces the severity and persistence of complications related to measles. $^{22-25}$

\section{Diarrhoea}

Children assigned to the vitamin A supplementation arms of the community based mortality trials had one third fewer deaths attributable to diarrhoea than the control subjects (table 2). Community based studies on the effect of supplementation on morbidity support these results: although supplementation did not reduce the incidence of diarrhoea, it did reduce the severity of subsequent diarrhoeal episodes. ${ }^{40}$ The lack of apparent impact on incidence may be real; alternatively, it may reflect an inadequate sample size given the high frequency of trivial diarrhoeal episodes among children in the developing world. ${ }^{8}$

\section{Respiratory disease}

Despite evidence for an association between vitamin A deficiency and the prevalence and incidence of respiratory disease ${ }^{8}{ }^{18}$ the prophylaxis trials did not show a consistent impact on death from respiratory disease (table 2). Indeed, it has been suggested that vitamin A supplementation may increase the risk of respiratory infection, though a World Health Organisation Consultative Group, after reviewing all available data, concluded that this was unlikely. ${ }^{26}$ Some workers have suggested that the apparent contradiction may reflect the reversal of squamous metaplasia of the epi-

Table 1 Major community mortality prevention trials

\begin{tabular}{|c|c|c|c|c|}
\hline Study & Country & Vitamin A supplement & $\begin{array}{l}\text { Reported mortality reduction } \\
(\%)^{\star}\end{array}$ & Primary reference \\
\hline Aceh & Indonesia & Large dose every six months & $34+$ & Sommer et $a l^{2}$ \\
\hline Bogor & Indonesia & Vitamin A fortified monosodium glutamate & 45 & Muhilal et $a l^{10}$ \\
\hline NNIPS & Nepal & Large dose every four months & 30 & West $e$ t $a l^{11}$ \\
\hline Jumla & Nepal & One large dose, follow up at five months & 29 & Daulaire $e t a l^{12}$ \\
\hline Tamil Nadu & India & Weekly moderate dose & 54 & Rahmathullah et al ${ }^{15}$ \\
\hline Hyderabad & India & Large dose every six months & $6($ not SS $) \ddagger$ & Vijayaraghavan et al $^{13}$ \\
\hline Khartoum & Sudan & Large dose every dix months & $(+6 ; \operatorname{not} \mathrm{SS})$ & Herrera $e t a l^{16}$ \\
\hline VAST & Ghana & Large dose every four months & 19 & Ghana VAST Study Team $^{14}$ \\
\hline
\end{tabular}

* 6 months and older at baseline ( 1 year or older if younger children not reported separately).

† Alternative analyses suggest at least 40 to $>50 \%$.

$\ddagger$ As calculated from data in their publication, but not reported as such. ${ }^{9}$

SS $=$ statistically significant $(\mathrm{p}<0.01)$.

Reprinted with permission from Sommer A, West KP. Vitamin A deficiency: health, survival, and vision. New York and Oxford: Oxford University Press, 1996.

Table 2 Cause specific mortality, vitamin A supplementation community prevention trials

\begin{tabular}{|c|c|c|c|c|c|c|}
\hline \multirow[b]{3}{*}{ Study } & \multicolumn{6}{|c|}{ Symptoms/diseases } \\
\hline & \multicolumn{2}{|l|}{ Measles } & \multicolumn{2}{|l|}{ Diarrheoa } & \multicolumn{2}{|l|}{ Respiratory } \\
\hline & Vitamin $A$ & Control group & Vitamin A & Control group & Vitamin $A$ & Control group \\
\hline \multicolumn{7}{|l|}{ Tamil Nadu ${ }^{15}$} \\
\hline No of deaths & 7 & 12 & 16 & 33 & 2 & 3 \\
\hline $\mathrm{RR}^{\star}$ & 0.58 & & 0.48 & & 0.67 & \\
\hline \multicolumn{7}{|l|}{ NNIPS $^{11}$} \\
\hline No of deaths & 3 & 12 & 39 & 62 & 36 & 27 \\
\hline $\mathrm{RR}$ & 0.24 & & 0.61 & & $1.29 / 1.00 \dagger$ & \\
\hline \multicolumn{7}{|l|}{ Jumlaq $^{12}$} \\
\hline No of deaths & 3 & 4 & 94 & 129 & 18 & 17 \\
\hline RR & 0.67 & & 0.65 & & $0.95 \ddagger$ & \\
\hline \multicolumn{7}{|l|}{ Ghana $^{14}$} \\
\hline No of deaths & 61 & 72 & 69 & 111 & 47 & 45 \\
\hline $\mathrm{RR}$ & 0.82 & & $0.66 \rrbracket$ & & 1.00 & \\
\hline
\end{tabular}

$\star \mathrm{RR}$ (relative risk): cause specific mortality of vitamin A group divided by mortality in control group.

† Original published result $\mathrm{s}^{11}: \mathrm{RR}=1.29$; reanalysis as an associated cause that recognises underlying causes; $\mathrm{RR}=1.00$ (KP West, unpublished data).

$\ddagger$ Pneumonia case management programme may have confounded results.

$\int$ Defined as 'acute gastroenteritis'.

I Except for Jumla, findings relate to children already $\geqslant 6$ months of age when supplemented.

Reprinted with permission from Sommer A, West KP. Vitamin A deficiency: health, survival, and vision. New York and Oxford: Oxford University Press, 1996. 
thelial lining of the respiratory tract, increasing its ability to mount a clinically detectable response to an infection. A definitive answer awaits further investigation.

\section{Young infants}

Few data suggest that vitamin A supplementation dramatically reduces childhood mortality in infants younger than 6 months of age. The only carefully conducted community based prophylactic trial even suggests the potential for a small increase in mortality among children supplemented with vitamin A during the second and third months of life; clear cut protection is evident by the age of 5 months. ${ }^{87}$ Whether this is a real effect or chance variation awaits the results of follow up investigations.

In one trial Indonesian children randomised to receive $50000 \mathrm{IU}$ vitamin A at birth had only half the first year mortality of control subjects. ${ }^{28}$ Almost all the benefit occurred during the second to fourth months of life.

\section{Non-infectious morbidity}

Apart from infectious disease, vitamin A status appears to play an important part in growth and haemoglobin synthesis. Human data on growth, particularly from controlled intervention trials, are confusing: from no impact at all to an age dependent influence on ponderal and/or linear growth. ${ }^{8}$ Presumably vitamin A can be a limiting factor of many aspects of the growth process, but the degree (if any) depends on the relative adequacy of other nutrients. In contrast, numerous studies have shown that improvement in vitamin A status favourably affects iron metabolism, reducing the severity of anaemia. ${ }^{810} 28$

\section{Mechanism of action}

The protective effects of vitamin A supplementation seem to be entirely related to restoring normal vitamin A status. This, in turn, increases resistance to (severe) infection through at least two mechanisms: the restoration of normally differentiated epithelia, providing a more effective barrier to infection; and up-regulation of immune competence. $^{8}$

For example, children admitted to hospital with severe measles who were randomised to vitamin A supplementation developed a far greater immune response than control subjects. ${ }^{25}$ The speed of the protective response, graphically illustrated by the $50 \%$ reduction in mortality from measles among children supplemented with vitamin A after admission to hospital, seems at first glance surprising. We now know, however, that vitamin A regulates the expression of at least 300 different genes and that the nasogastric administration of vitamin A to deficient rats results in detectable alterations in gene products within an hour. ${ }^{8}$ Hence the dramatic clinical response observed in hospital and field studies has a readily demonstrable biological basis, even if it is only currently partially understood.

\section{Recommendations for prophylaxis}

The ultimate goal of prophylaxis is to restore normal vitamin A status to deficient children. The most effective means for accomplishing this urgent task will depend on the vagaries of local culture, the available foods, and the local health system. Ideally, every child (and woman) should receive adequate vitamin $\mathrm{A}$ as part of their regular diet. Small daily doses are more efficiently absorbed and stored than large periodic supplements. Unfortunately, the population of those countries in which the problem is most severe and extensive subsist primarily on vegetable diets, containing little, if any, preformed vitamin A (aside from breast milk, which is an excellent source for the young

\section{Key messages}

- Vitamin A deficiency increases the severity of and mortality from measles and diarrhoea

- Increased infectious morbidity and mortality is apparent even before the appearance of xerophthalmia - Improving the vitamin A status of deficient children aged 6 months to 6 years can dramatically reduce their morbidity and mortality from infection

- Prompt administration of large doses of vitamin A to children with moderate to severe measles, particularly if they may be vitamin A deficient, can reduce individual mortality by $50 \%$ and prevent or moderate the severity of complications

infant). Provitamin A carotenoids found in many fruits and vegetables are inefficiently converted to the active agent and one of the best, most widely available sources of provitamin A carotenoids, dark green leafy vegetables, is commonly eaten in only small amounts, if at all, by young children.

Many wealthier countries rid themselves of the problem through the fortification of dietary staples, particularly margarine and bread. Fortification of sugar has proved to be an effective approach for dramatically reducing the prevalence and severity of vitamin A deficiency in Guatemala and is now being instituted in a number of other Latin American countries.

Where the problem is most severe, however, particularly in Africa and Asia (India, Bangladesh, Pakistan, Indonesia, and the Philippines), periodic supplementation of every child once every three to six months (100 000 IU at less than 1 year of age; 200000 IU for older children) is recommended. Children at special risk (for example severe protein energy malnutrition, chronic diarrhoea, repeated respiratory infection) are provided with an additional dose if they have not received routine prophylaxis within the past month. Measles is treated with a 200000 IU supplement on two successive days as a medical emergency. To boost maternal stores and the amount of vitamin A in breast milk, women are advised to receive 200000 IU within four to six weeks of delivery.

Over 60 countries are now planning, or have instituted, programmes to control vitamin A deficiency. Periodic supplementation as a special endeavour generally achieves sustainable coverage rates of $40-60 \%$, though some countries (and most demonstration projects) attain far higher levels. In Indonesia, where distribution has been integrated into a burgeoning health service system and mass media has been used to educate the public and change dietary patterns, a $90 \%$ reduction in the prevalence of overt deficiency has been achieved. ${ }^{8}$

Unquestionably, the major challenge remains the design and implementation of effective population based intervention programmes.

\section{Conclusions}

Although there is a great deal more to be learnt about the value of vitamin A status and childhood morbidity and mortality, there is no longer any credible doubt that deficiency is inimical to optimum health and survival. These effects begin to occur even before the appearance of ocular disease ('xerophthalmia'). ${ }^{82}$

ALFRED SOMMER

fohns Hopkins School of Hygiene and Public Health,

615 North Wolfe Street,

Baltimore,

$M D$ 21205-2179, USA 
1 Sommer A, Hussaini G, Tarwotjo I, Susanto D. Increased mortality in children with mild vitamin A deficiency. Lancet 1983;ii:585-8.

2 Sommer A, Tarwo I, Djumaedi E, et al Impact of vitamin A supplen tionm A, Tarwotjo I, Djunaedi E, et al. Impact of vitamin A supplementation on childhood mortality. A randomised controlled community trial Lancet 1986;i:1169-73

3 Tarwotjo I, Sommer A, West KP, et al. Influence of participation on mortality in a randomised trial of vitamin A prophylaxis. Am f Clin Nutr 1987;45:1466-71

4 United Nations/Activities Coordinating Committee/Subcommittee on Nutrition. Focus on micronutrients. SCN News 1993;9:1-66.

5 World declaration and plan of action for nutrition. International Conference on Nutrition. Rome: Food and Agriculture Organisation and the World Health Organisation, 1992.

6 National strategies for overcoming micronutrient malnutrition. 45th World Health Assembly (agenda item 21). Geneva: World Health Organisation, 1992.

7 World Bank. World development report 1993: investing in health. Washington DC: World Bank/New York: Oxford University Press, 1993.

8 Sommer A, West KP. Vitamin A deficiency: health, survival, and vision. New York and Oxford: Oxford University Press, 1996.

9 Beaton GH, Martorell R, L'Abbe KA, et al. Effectiveness of vitamin A supplementation in the control of young child morbidity and mortality in developing countries. Toronto: University of Toronto; 1992. Final Report to CIDA

10 Muhilal, Permeisih D, Idiradinata YR, Muherdiyantiningsih, Karyadi D. Vitamin A-fortified monosodium glutamate and health, growth, and survival of children: a controlled field trial. Am f Clin Nutr 1988;48:12716.

1 West KP Jr, Pokhrel RP, Katz J, et al. Efficacy of vitamin A in reducing preschool child mortality in Nepal. Lancet 1991;338:67-71

12 Daulaire NMP, Starbuck ES, Houston RM, Church MS, Stukel TA, Pandey MR. Childhood mortality after a high dose of vitamin A in a high risk population. BMf 1992;304:207-10

13 Vijayaraghavan K, Radhalah G, Prakasam BS, Sarma KVR, Reddy V. Effect of massive dose vitamin A on morbidity and mortality in Indian children. Lancet 1990;ii: 1342-5.

14 Ghana VAST Study Team. Vitamin A supplementation in northern Ghana: effects on clinic attendances, hospital admissions, and child mortality. Lancet 1993;342:7-12.

15 Rahmathullah L, Underwood BA, Thulasiraj RD, et al. Reduced mortality among children in Southern India receiving a small weekly dose of vitamin A. $N$ Engl f Med 1990;323:929-35.
16 Herrera MG, Nestel P, El Amin A, Fawzi Ww, Mohamed KA, Weld L. Vitamin A supplementation and child survival. Lancet 1992;340:267-71.

17 Fawzi WW, Chameres TC, Herrera MG, Mosteller F. Vitamin A supplementation and child mortality. $\mathcal{F} A M A$ 1993;269:898-903.

18 Sommer A, Hussaini G, Muhilal, Tarwotjo I, Susanto D, Saroso JS. History of nightblindness: a simple tool for xerophthalmia screening. Am f Clin Nutr 1980;33:887-91.

19 Milton RC, Reddy V, Naidu AN. Mild vitamin A deficiency and childhood morbidity-an Indian experience. Am f Clin Nutr 1987;46:827-9.

20 Barreto ML, Santos LMP, Assis AMO, et al. Effect of vitamin A supplementation on diarrhoea and acute lower-respiratory-tract infections in young children in Brazil. Lancet 1994;344:228-31.

21 Ellison JB. Intensive vitamin therapy in measles. BMF 1932;ii:708-11.

22 Barclay AJG, Foster A, Sommer A. Vitamin A supplements and mortality related to measles: a randomised clinical trial. BMF 1987;294:294-6.

23 Hussey GD, Klein M. A randomised, controlled trial of vitamin A in children with severe measles. N Engl F Med 1990;323:160-4

24 Coutsoudis A, Broughton M, Coovadia HM. Vitamin A supplementation reduces measles morbidity in young African children: a randomised, placebo-controlled, double-blind trial. Am f Clin Nutr 1991;54:890-5.

25 Coutsoudis A, Kiepiela P, Coovadia HM, Broughton M. Vitamin A supplementation enhances specific IgG antibody levels and total lymphocyte numbers while improving morbidity in measles. Pediatr Infect Dis $\mathcal{F}$ 1992;11:203-9.

26 Sommer A, Rahmathullah L, Underwood B, et al. Potential interventions for the prevention of childhood pneumonia in developing countries: a meta-analysis of data from field trials to assess the impact of vitamin A supplementation on pneumonia morbidity and mortality. Bull WHO 1995;73: 609-19.

27 West KP Jr, Katz J, Shrestha SR, et al. Mortality of infants $<6$ mo of age supplemented with vitamin A: a randomised, double-masked trial in Nepal. Am f Clin Nutr 1995;62:143-8.

28 Humphrey JH, Agoestina T, Wu L, et al. Impact of neonatal vitamin A supplementation on infant morbidity and mortality. F Pediatr 1996;128:48996.

29 Mejia LA, Chew F. Haematological effect of supplementing anaemic children with vitamin $\mathrm{A}$ alone and in combination with iron. Am f Clin Nutr 1988;48:595-600.
Routine neonatal male circumcision as policy excites strong medical opinions both for and against. In the USA over $70 \%$ of all males have been circumcised ${ }^{1}$ while the UK's national survey of sexual attitudes and lifestyles found in 1990/1 that $21 \%$ of adult males (aged 16-59 years) reported having been circumcised. ${ }^{2}$ The percentage was $13 \%$ among those aged $16-24$ years but $32 \%$ for those 45-59 years indicating that British rates have declined recently, ${ }^{2}$ as they may also have done in the USA. ${ }^{3}$ Circumcision rates are intermediate in Canada $^{1}$ but very low in the Nordic countries. ${ }^{4}$ These large intercountry differences are not explicable on religious grounds. ${ }^{12}$ They are best explained on grounds of medico/social culture and fashion, as is the case for some other elective surgical procedures of uncertain effectiveness. ${ }^{15}$

The case for routine male circumcision has rested most firmly on the observation that rates of infant urinary tract infection and adult penile cancer are lower in circumcised males. ${ }^{6}$ However when weighed against the irreducible complication rates and costs of the procedure, these are thought insufficient grounds to recommend routine circumcision. ${ }^{137}$ Recently added is the observation that circumcised males seem less likely to acquire infection with HIV-1, or other sexually transmitted diseases (STDs). ${ }^{8}$ Four explanations have been suggested ${ }^{9}$ : firstly that the exposed glans penis may develop a protective layer of keratin (sometimes referred to as a 'natural condom'); secondly that the foreskin may be especially susceptible to minor balanitis and trauma during intercourse, allowing movement of HIV-1 through the dermatological barrier; thirdly that the warm microclimate under the foreskin may permit micro-organism survival increasing exposure to potential infections; and fourthly that lack of circumcision may predispose to a coinfection with other STDs that are known to facilitate heterosexual HIV-1 transmission. ${ }^{10}$

Many observational studies provide data relevant to the relationship of HIV-1 infection and circumcision, and these have been the subject of two reviews and one meta-analysis of multiple studies within one region of an African country. ${ }^{911} 12$ The studies have been of types described as cross sectional or retrospective (observing the relative risk of being HIV-1 infected in circumcised and uncircumcised men, or their female partners), prospective observational (observing the risk of becoming HIV-1 infected among circumcised and uncircumcised men), and ecological (comparing the association between circumcision status and prevalence of HIV-1 in different populations). Heterosexual partnership studies have also looked at sexual partners of men or women diagnosed HIV-1 infected in relation to the male's circumcision status. The reviews note the data's limitations. ${ }^{91112}$ Most were gathered in African or other developing countries where incidence and prevalence of HIV-1 was sufficiently high to investigate possible effects of circumcision. None of the studies was experimental (no-one has dared 'trial' circumcision), nor were they primarily designed to investigate the HIV-1 and circumcision relationship. Therefore most are subject to confounding factors and many lack optimal statistical power. That said most, but not all, the African studies found the risk of HIV-1 infection was reduced among circumcised men. ${ }^{911} 12$ The reductions were modified by location, social status, religion, and background HIV-1 